\begin{tabular}{cccc}
\hline Bentham open & The Open Petroleum Engineering \\
CrossMark & Journal \\
\hline
\end{tabular}

RESEARCH ARTICLE

\title{
Analysis on Production of Coal Bed Methane Considering the Change in Permeability of Coal Rock
}

\author{
Zhu Likai $^{1,2}$, Ji Youjun ${ }^{3,4, *}$, Yang Tianhong ${ }^{1}$ and Li Xiaoyu ${ }^{3}$ \\ ${ }^{1}$ Center for Rock Instability and Induced Seismicity Research, Northeast University, Shenyang 110819, China \\ ${ }^{2}$ Shenyang Research Institute of China Coal Science and Industry Group, Shenyang 110016, China \\ ${ }^{3}$ State Key Laboratory of Oil and Gas Reservoir Geology and Exploitation (Southwest Petroleum University), Chengdu, \\ 610500, China \\ ${ }^{4}$ School of Geoscience and Technology, Southwest Petroleum University, Chengdu, 610500, China
}

Received: July 22, 2016

Revised: August 25, 2016

Accepted: October 31, 2016

\begin{abstract}
Based on the mechanism of migration of the coal bed methane (CBM), and taking into account the deformation of the coal rock during the process of $\mathrm{CBM}$ production was also taken into account, a coupled mathematical model considering the interaction of solid and fluid for methane extraction was built. The coal gas extraction of JINcheng coal mine was taken as an example, some typical coal sample was chosen to test the permeability under different confining pressure. The curve for permeability of coal rock versus effective stress under different confining pressure was obtained, a numerical model considering the variation of permeability for methane extraction was set up. The influence of deformation of coal rock on the gas production was simulated and analyzed. The simulation results indicate that the productivity curve considering deformation of rock is closer to the actual production data, at the initial stage of production, the gas rate is less than the case without considering deformation of rock, but the time of stable yield will last longer, and this matches the actual methane extraction, therefore, we recommend that the deformation of coal seam should be considered during the prediction of methane production for JINcheng coal mine.
\end{abstract}

Keywords: Deformation, Methane, Numerical Simulation, Prediction for production of CBM.

\section{INTRODUCTION}

The CBM exists in the coal seam in the form of adsorption, which is different from the ordinary natural gas. The main method for the exploitation of CBM is to drain the water in the coal rock (to get the water out from the stratum) to extract the gas, competitive adsorption and fracturing et al. [1 - 4], as for the mathematical model and mechanism for the development of coalbed methane, many scholars have conducted a lot of research work.

It is commonly recognized that the properties of coal are gradually changed during the process of production of methane. As far as the research on properties of coal rock are concerned, GUO et al. [5] employed MZY- type I permeability measuring instrument of coal seam to measure permeability of gas in coal seam under different pressure. Zhang et al. [6] took triaxial compression test under condition of different coal gas pressure and confining pressure of coal samples, and studied seepage characteristics of well circumferential and influence of gas seepage on the mechanical properties of coal and rock. LI et al. [7] took the No. 9 coal seam and completion fluid in Ningwu basin as the research object, and carried out the experiment on desorption of coalbed methane, capillary imbibition and drilling and completion fluid dynamic-static damage, and analyzed mechanism of the drilling and completion fluids affecting CBM desorption-diffusion-seepage by means of the micro methods. YIN et al. [8] took the molding coal sample in Jincheng coal industry group in Zhaozhuang Mine as the research object and simulated the influence of changes of

\footnotetext{
* Address correspondence to this author at the State Key Laboratory of Oil and Gas Reservoir Geology and Exploitation (Southwest Petroleum University), Chengdu, 610500, China; Tel: +86 18380172978; E-mail: jiyoujun0319@163.com.
} 
moisture content in coal-bed on seepage of coalbed gas. LI et al. [9] studied the relationship between permeability of coal samples and effective stress and movement law of coal gas and established equations of permeability and effective stress to describe nonlinear seepage law of methane.

Based on the experimental results, ZHANG et al. [10] established a mathematical model of nonlinear seepage flow in coal seam, which can clearly characterize the flow resistance and the physical meaning. LIANG et al. [11] carried out the research work about the law of interaction between the deformation and gas seepage in coal rock. According to the characteristics of gas flow in coal seams, considering the dynamic change of permeability, gas adsorption and desorption in micro porous gap, they established a coupled seepage model. From the perspective of seepage field and the stress field, SONG et al. [12] established a model with non uniform distribution of the water bearing layer in the bottom plate and the model of the strip zone considering the interaction of fluid and structure. Based on elastic plastic theory, the elastic and plastic solution of the limit water pressure of the water inrush from coal seam floor were obtained. On the basis of mass and momentum conservation equations of seepage theory, SONG et al. [13] established a non Darcy percolation mathematical model, and by considering desorption effect of methane and low velocity they deduced the radial flow pressure distribution analytic solution and deliverability equation of this new coal-bed methane.

About the numerical simulation of coalbed methane, the trend is that, the transportation ability of coal rock should be considered as variable. LI et al. [14] used the constant permeability, the stress sensibility and S-D model of cleat with changing compression ratio to describe the coal seam respectively, employed the software Simed to study the drainage intensity of coal seam with different structure. ZHANG et al. [15] used COMSOL to simulate the change of gas desorption and seepage in the non isothermal coal bed under the condition of convection-solid-thermal coupling. $\mathrm{XU}$ et al. [16] used briquette specimen as the object for study, tested permeability evolution of coal bed under the condition of different temperature and different confining pressure. JIANG et al. [17] used the multi physical field coupling simulation software COMSOL to simulate the gas seepage process in coal seam during water injection, and analyzed the variation of water saturation in the front of water and gas in discontinuous interface. In consideration of deformation capacity from adsorption, compressibility of pore gas and thermal expansion. YAO et al. [18] used the flow solid coupling analysis module of three dimensional fast Lagrangian (FLAC3D) and considering the variable permeability of the rock on working face floor they studied the dynamic mechanism of strain and seepage of mining.

To sum up, in drainage of water to recover coal gas, the production of fluid, leads to the continuous change of pore pressure and reorientation of formation stress and finally changes the physical parameters of bed rock. Among these dynamic changes in the parameters, the permeability properties of coal and rock will significantly affect the well productivity of coal bed methane. Therefore, it is necessary to analyze the change of permeability of coal seam resulted from variation of seepage field, and hence to explore that how this affects the productivity of coal seam gas.

The development of coal-bed gas in Jincheng coal mine is taken as instance, after the test of permeability for typical coal and rock under different confining pressure and gas pressure based on the logging data and experimental results of coal seam, the geological model of the coal bed was established. According to practical dynamic production data, the numerical model of a block including one single methane well was established, numerical analysis of gas development of the well was conducted reveal the law about deformation of coal and rock affecting development of coal bed methane.

\section{MATHEMATICAL MODEL OF MIGRATION OF COAL BED METHANE}

The coal bed gas reservoir has a dual porosity structure, which is composed of the coal matrix and the fracture system, and the methane gas mainly exists in the coal matrix in the state of adsorption. A small amount of free gas exists in the fracture system, in the extraction of coal bed methane, with the drop of reservoir pressure, equilibrium of gas adsorption is broken, the gas adsorbed in coal matrix will escape from the matrix and diffuse into the crack system and be extracted from the fracture. Therefore, compared with the flow process of traditional underground water and oil resources, the migration of coal bed gas is more complex, it includes process of diffusion of gas in the coal matrix, and seepage process in fracture system. At the same time, different flow characteristics in different mobile phases, the escaping and diffusion process can be described by the Langmuir isotherm adsorption equation and the Fick's diffusion law [19], the flow process in cracks can be described by Darcy and non Darcy's law, accompanied by deformation of reservoir and molecular diffusion effects of gas. 


$$
c\left(p_{f}\right) \frac{\partial p_{f}}{\partial t}-\nabla\left(K\left(p_{f}\right) \nabla p_{f}\right)=q_{m}
$$

As we did not consider the changing of the temperature during the simulation, the process we simulated was set as isothermal. The mathematical model of methane migration considering deformation of coal bed is as follows, mainly including two processes, one is the seepage model in fracture system.

The other one is the diffusion equation in coal matrix,

$$
\frac{d C_{a m}}{d t}=D_{m} \sigma\left(C_{E}\left(p_{f}\right)-C_{a m}\right)
$$

The boundary conditions for constant pressure:

$$
p_{f}=p_{0}
$$

The initial conditions for initial concentration of coal bed methane:

$$
C_{a m}=C_{0}
$$

Where, $C_{a m}$ is the concentration of coal bed methane, $D_{m}$ is the diffusion coefficient of gas, $p_{f}$ is the pressure of gas, $C_{E}$ is the concentration of gas in the fracture, $c$ is the compression coefficient of gas, $K$ is the permeability tensor of coal rock, $q$ is source and sink item, here means the flux from the matrix to the crack system.

During the process of CBM production, the pore pressure is constantly changed, and the stress of the rock skeleton is also altered. This phenomenon can be described by the principle of effective stress, considering the equilibrium equation for the coal rock, the final equilibrium equation of coal rock during the production of methane can be expressed as follows:

$$
\sigma_{i j}=\sigma_{i j}^{\prime}+\alpha p \delta_{i j}
$$

Where $\sigma_{i j}$ is the total stress in the porous media, $\sigma_{i j}$ is the effective stress, $p$ is the pore pressure, which can be calculated from equation (1), $\delta_{i j}$ is the Kronecker Delta; and $\alpha$ is the Biot constant $(0 \leq \alpha \geq 1)$.

Due to the changing of effective stress and pore pressure of the coal rock, the permeability and porosity will be changed [20], this can be described by an empirical relationship between the permeability and the pore pressure, effective stress, etc. There are many empirical expressions of this kind, they can be represented by the following equation:

$$
K=K\left(\sigma_{i j}^{\prime}, p\right)
$$

\section{EXPERIMENT ON DEFORMATION AFFECTING PERMEABILITY OF COAL SEAM}

In order to simplify the mathematical model and the calculation process of simulation, we consider that the deformation of coal rock will mainly result in the variation of permeability of rock. The final results of changing of stress field is to alter the gas pressure and cause the variation of permeability. Therefore, we just designed some experiments to test the permeability of coal rock under different confining pressures. The equipment for testing the permeability of rock under axial compression and confining pressure is shown in Fig. (1). The oil system was used to load the confining pressure, and the axial compression system to load the axial pressure to the sample. The axial compression sensor was used for monitoring and measuring the axial pressure on the sample, collection system for stress information was used for measuring the stress, strain, and displacement of the coal sample, and the test was set as isothermal.

In order to obtain the law that the deformation of coal rock affect the permeability, we set the confining pressure as $2 \mathrm{MPa}, 4 \mathrm{MPa}, 6 \mathrm{MPa}, 8 \mathrm{MPa} 12 \mathrm{MPa}, 15 \mathrm{MPa}$ to test the permeability of coal rock. The high temperature and high 
pressure multi function parameter measuring instrument and triaxial testing apparatus from state key laboratory of oil and gas reservoir geology and exploitation (Southwest Petroleum University) were used to test the permeability of coal rock, the samples of coal rock from Jincheng coal mine we used for the experiments are shown in Fig. (2)

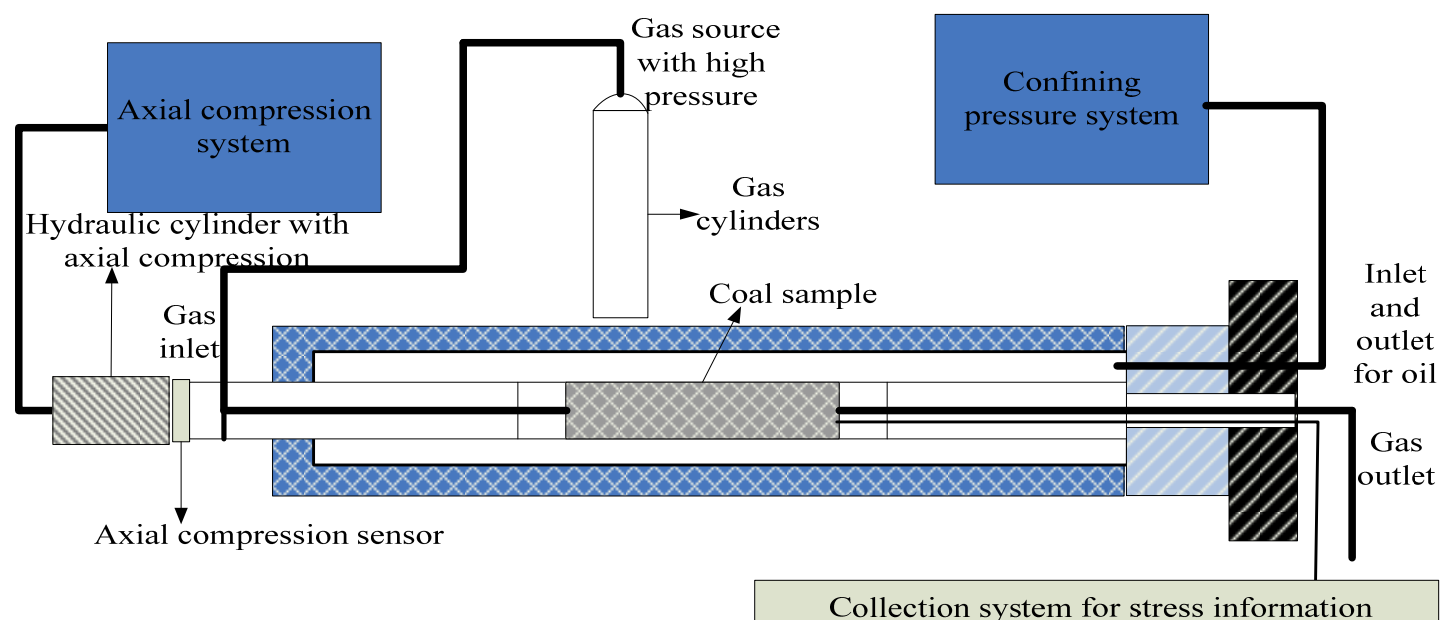

Fig. (1). The equipment for testing the permeability of rock under axial compression and confining pressure.

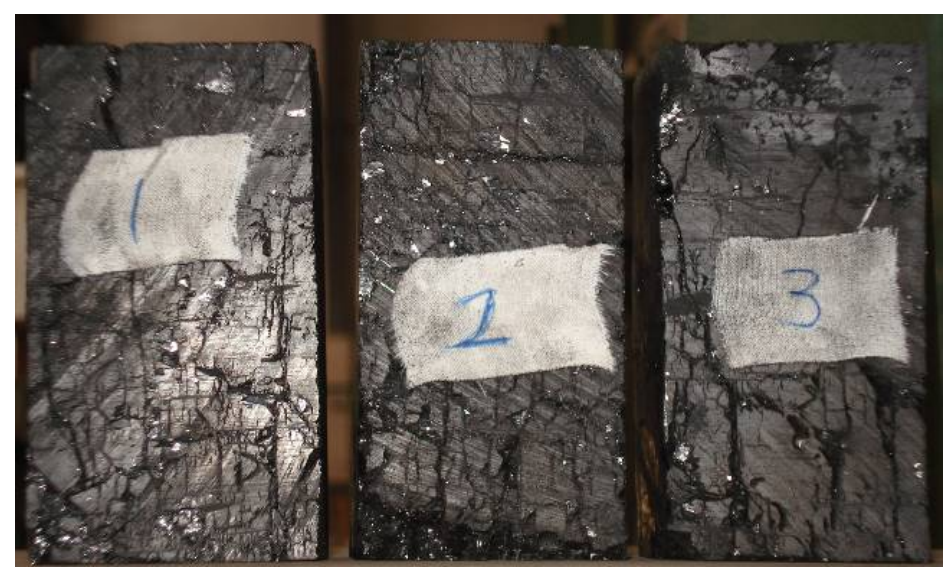

Fig. (2). Samples of the coal rock.

The depth, from where to get the samples above is about $400 \mathrm{~m}$, the stratum belongs to the Taiyuan formation. Stone carbon series, the average thickness of the stratum containing coal is about $50 \mathrm{~m}$. The retrieved coal rock were cut into standard coal samples in accordance with the recommended standard from the ISRM, the scale of the samples is 50 $\mathrm{mm} \times 50 \mathrm{~mm} \times 100 \mathrm{~mm}$.

The formula below was used to calculate the permeability of the coal sample in the experiment.

$$
k=\frac{2 q p_{2} \mu L}{A\left(p_{1}^{2}-p_{2}^{2}\right)}
$$

where, $k$ is the permeability of the coal sample, $q$ is the flux of coal gas under the standard condition, $\mu$ is the dynamic viscosity of the coal gas, $L$ is the length of the sample, $A$ is the Cross-sectional area of the sample, $p_{2}$ is the pressure of coal gas at the outlet, $p_{1}$ is the pressure of coal gas at the inlet.

The curves of permeability vary with the gas pressure under different confining pressures are shown in Fig. (3).

As can be observed from the figure above, with the increase of effective stress, the permeability of coal is getting 
smaller, when the effective stress is increased to a certain degree, the permeability of the coal rock will remain constant and become stable.

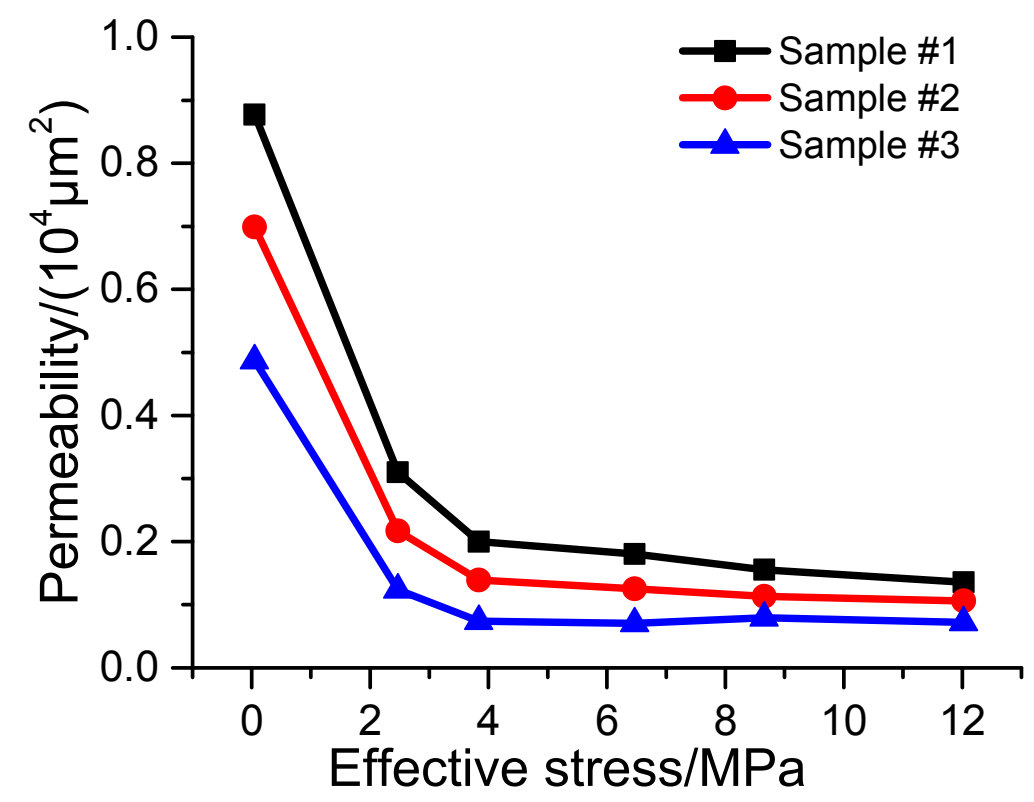

Fig. (3). Permeability vary with gas pressure under different effective stress.

The main reason for this trend is that the pore space and deformation of coal rock is limited at the elastic stage. When the porosity of coal rock is compressed to a certain level, it can not be compressed, the skeleton of the coal rock will stop deforming. Therefore, the permeability is also no longer changing, but this limit state is often difficult to reach in coal-bed methane mining process unless using crack method, usually, change of permeability is always before the critical point. That is to say, with the gradual decrease of pore pressure, the permeability will have a little decrease and end in a stable value.

From the test results above, it can be observed that permeability of coal bed is significantly sensible to stress. Therefore, for the coal bed methane reservoir, considering dependence of permeability on pressure in the process flow in fracture is very necessary. According to permeability with the pore pressure and confining pressure of the coal rock test results above, we introduce the permeability tensor, use exponential function to fit relationship between the permeability and reservoir pressure as follows:

$$
K=K_{0} e^{-\sigma_{i j}^{\prime}}
$$

Where, and $\mathrm{K}$ are initial gas pressure and permeability in coal rock, respectively.

Combining equation (5), by substituting this relationship to equation (8), the deformation of coal rock can be considered during the simulation of CBM production

\section{NUMERICAL SIMULATION OF DEVELOPMENT OF COAL BED METHANE FOR SINGLE WELL}

We used the CMG (Computer modeling group) 2012 to simulate the process of coal bed methane extraction, the CBM module in CMG can be used to simulate the process. There are two kinds of methods to consider the changing of permeability for $\mathrm{CMG}$, one is the empirical formula, only you need to input several parameters to set up the coupled simulation. The other one is to directly input the experiment results in the form of a table, such as the permeability VS effective stress or pore pressure, etc. We used the second method to consider the variation of the permeability of coal rock, it is an equivalent coupled method for simulation of CBM extraction considering deformation of coal rock.

The CHC38 layer in Jincheng coal mine was chosen as the research object, at present there are 45 wells in the main gas layer, including 12 testing wells produced for over 1 year, 18 wells over 9 months, 15 wells over 6 months, 35 wells over 3 months, and 10 wells in less than 3 months. Among these wells, CHC38 well is relatively independent, and the 
production time of the well is just 1 year, the production data is more complete, so we select the $\mathrm{CHC} 38$ well as the research well to analyze the variation of productivity.

The well CHC38 was set as the center of simulation zone, the scope about one well distance $100 \mathrm{~m}$ away from the well as its controlling area, the model specifications are as follows, number of grids at $\mathrm{x}, \mathrm{y}$ and $\mathrm{z}$ are 17, 19 and 16, the mesh size is $5 \mathrm{~m}, 5 \mathrm{~m}, 3 \mathrm{~m}$, the top depth of the coal seam is $400 \mathrm{~m}$, and water saturation ratio is 0.68 , initial porosity and permeability parameters of the numerical model is obtained by 3D DSI interpolation, according to well logging data, 3D geological and mesh model are shown in the Fig. (4).

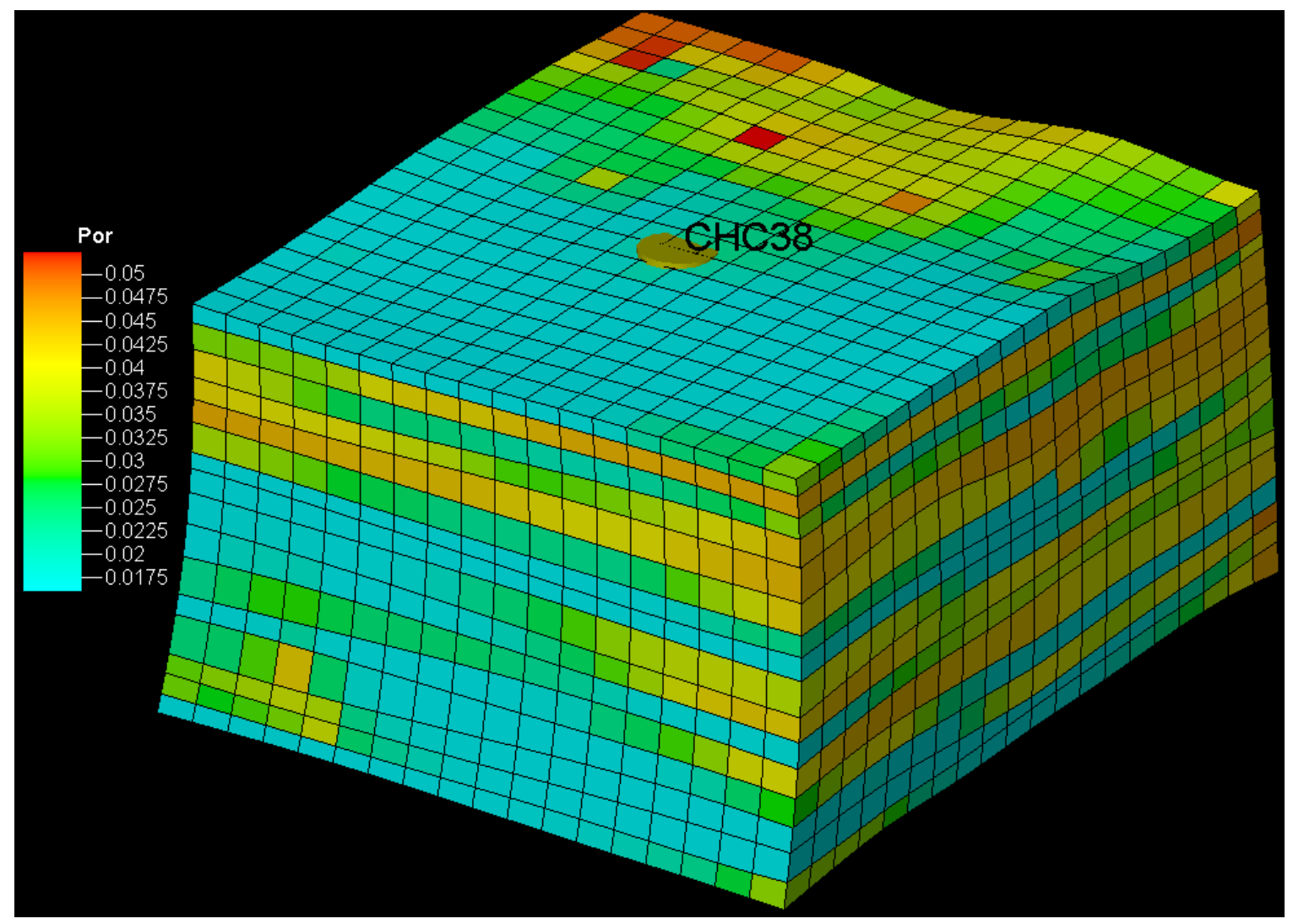

Fig. (4). Grid of geological and numerical model.

Boundary conditions of model: the production time of well is set as 1 year, this time is the actual production time, production pressure of the well is constant, the bottom hole pressure is $3 \mathrm{MPa}$. There is no flux between the boundary of the model and the outside, we choose no-flow B.C. The other necessary parameters are shown in Table 1 . The comparison curves of daily gas production and daily water production with and without consideration of permeability variation of coal and rock with the actual production data are given.

Table 1. The basic parameters of the model.

\begin{tabular}{|c|c|c|c|}
\hline & Value & Item & Value \\
\hline The top depth of the coal mine $/ \mathrm{m}$ & 400 & The scale of the model & $85 \mathrm{~m}^{*} 95 \mathrm{~m}^{*} 48 \mathrm{~m}$ \\
\hline Average thickness of the coal stratum $/ \mathrm{m}$ & 48 & Initial pressure $/ \mathrm{kPa}$ & 750 \\
\hline Average porosity & 0.04 & Initial methane content & $11.5 \mathrm{~m}^{3} / \mathrm{t}$ \\
\hline Average Permeability of matrix $/\left(10^{-3} \mu \mathrm{m}^{2}\right)$ & 0.05 & Density of coal rock $/\left(\mathrm{kg} / \mathrm{m}^{3}\right)$ & 1300 \\
\hline Average Permeability of fracture $/\left(10^{-3} \mu \mathrm{m}^{2}\right)$ & 0.5 & Initial stress $/ \mathrm{kPa}$ & 810 \\
\hline Biot's constants & 1.0 & fracture interval $/ \mathrm{m}$ & 40 \\
\hline
\end{tabular}

The gas rate and cumulative gas are given in Figs. (5 and 6), respectively. The process of CBM production with and without considering changing of permeability are both simulated, and the simulation results are compared with the production data. 


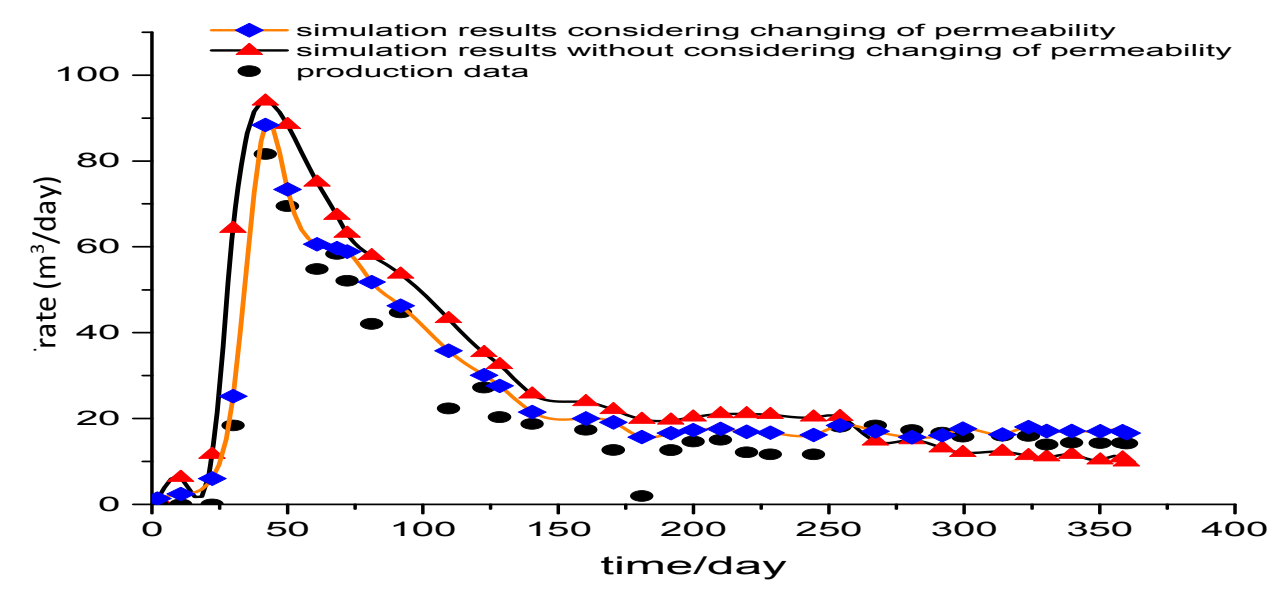

Fig. (5). Gas rate comparison of the well CHC38.

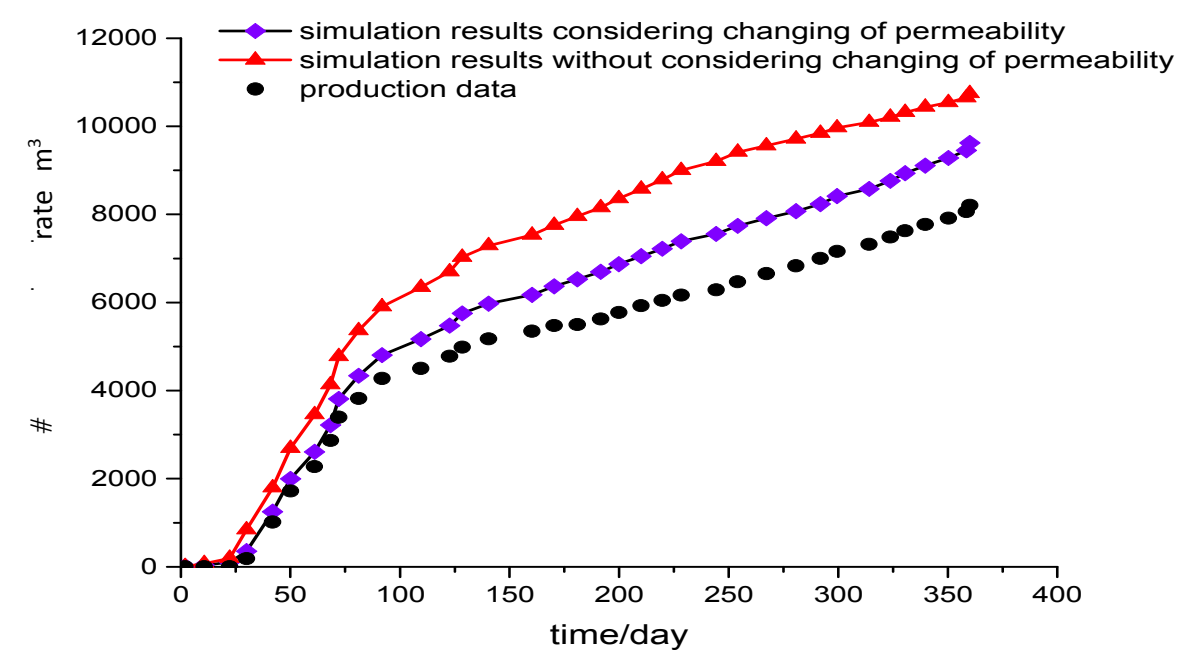

Fig. (6). Cumulative gas comparison of the well $\mathrm{CHC} 38$.

From Fig. (5), we can see that without considering the permeability change of coal and rock, daily production of coalbed gas is always higher than that of considering the deformation of coal and rock. No matter what the situation is, the calculated results of the coalbed methane production curve are always above the actual production data. At the early stages of production, there is no actual yield, and this span is shorter in simulation results. The gas rate is gradually increased from zero to the peak value, the main reason is that the dynamic equilibrium between adsorption and desorption of gas in numerical simulation is not taken into account. We just recognize that the coal bed gas directly and quickly migrated from the center of the matrix to the surface without transportation process. Gas production rate considering deformation of coal and rock is relatively close to actual production data, which shows that prediction of gas production rate with consideration of deformation is more reasonable, and the stable production period of coal seam gas will be longer for this case.

From Fig. (6), the cumulative gas for the simulation considering the variation of permeability is less than that without considering, which can be explained by the deformation of coal rock. According to the equation (5), (8) and the results of the experiments, it is obvious that the permeability of the coal rock will gradually decrease as the increase of the effective stress in the coal seam, which is resulted from the decrease of the pore pressure.

The gas content of this coal mine and the extraction method are just to drain water to take out methane and the productivity of this well is very low. It is necessary to employ the fracturing method to enhance the recovery factor of CBM.

The comparison of water rate and cumulative water for the well CHC38 is demonstrated in Figs. (7 and 8), respectively. 


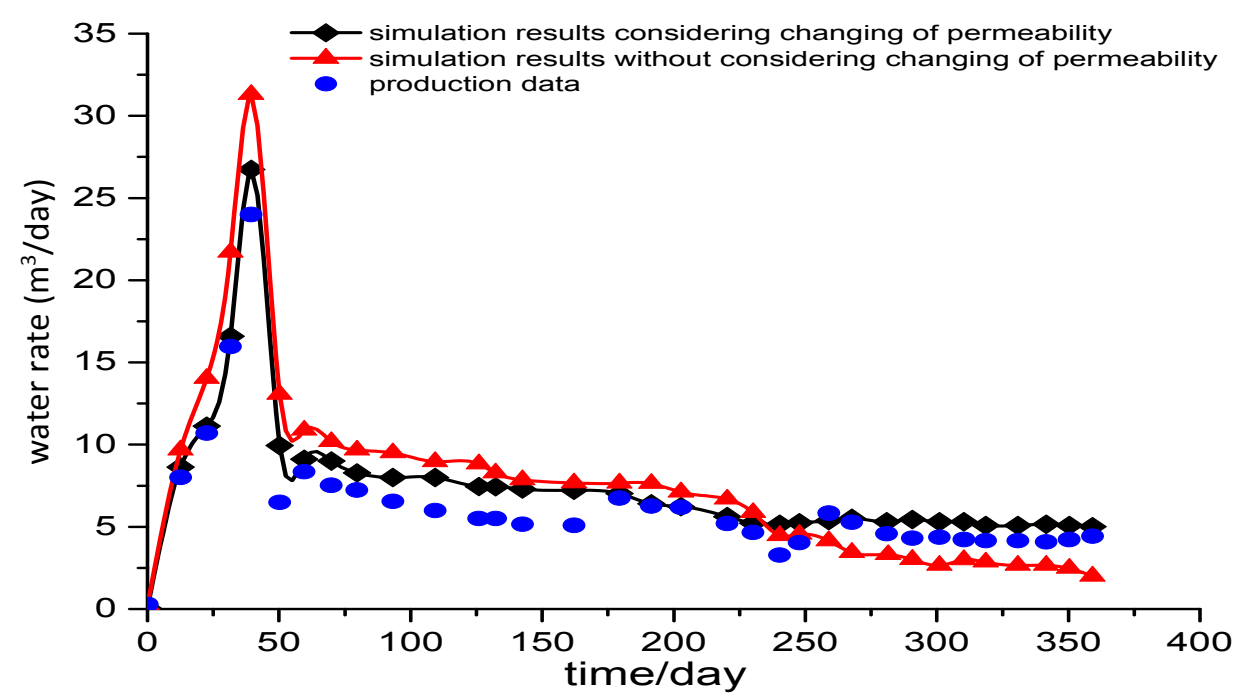

Fig. (7). Water rate comparison of the well CHC38.

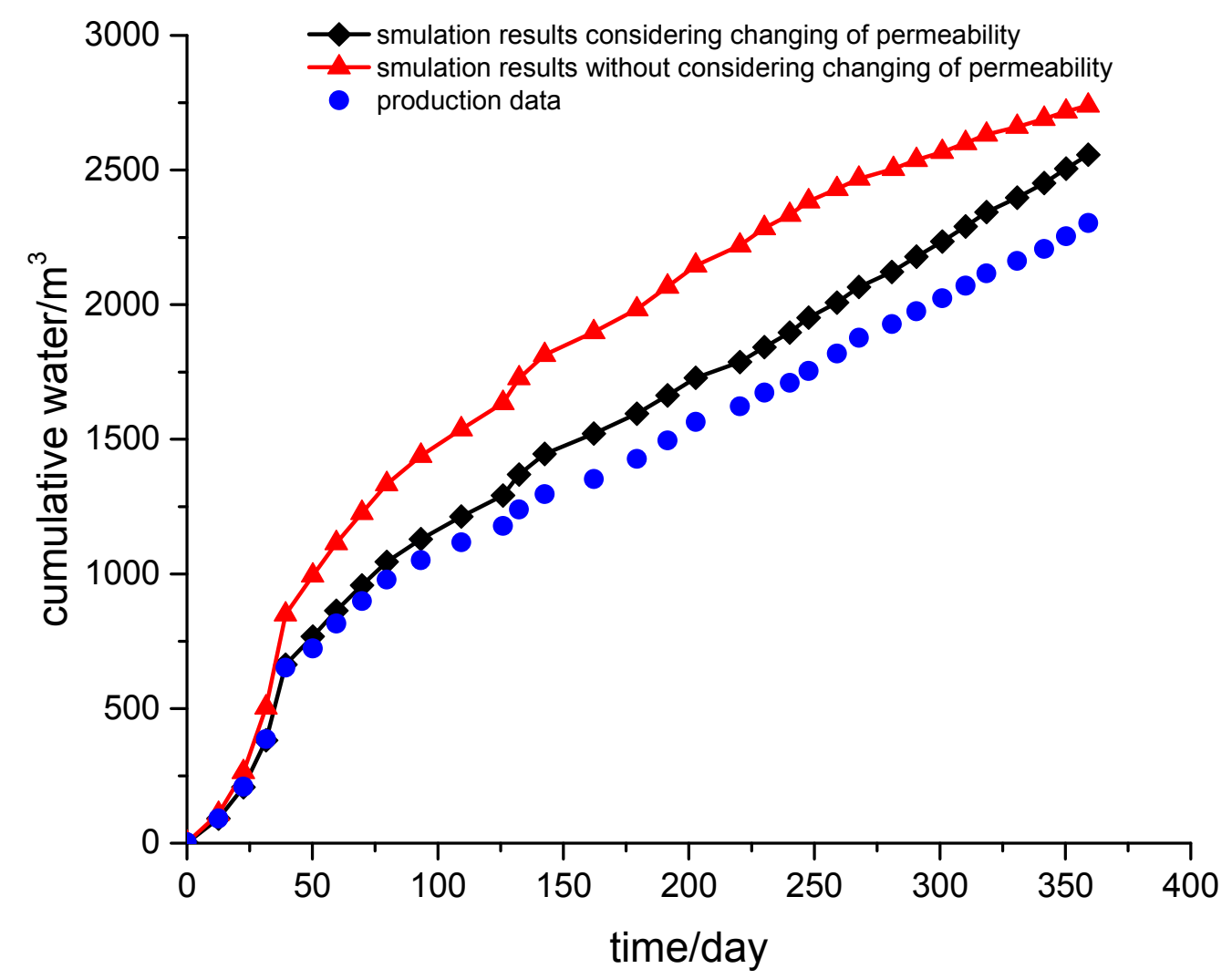

Fig. (8). Comparison of cumulative water for the well CHC38.

From Figs. (7 and 8), similar to gas rate curve, it can be observed that the water rate curve of consideration of deformation of rock is below the other case, and this is closer to the actual production data.

Therefore, in the prediction of methane production, considering the deformation of coal rock will be better and bring more accurate results. For production history matching of CBM, it is recommended to consider the influence of deformation of coal rock. As the deformation of coal rock is realized by fitting the results of permeability test under different pore pressures and confining pressures, no simulation of stress field is involved. In the future, we can consider the calculation of stress field in practical model to make fully coupled simulation and improve the accuracy. 


\section{CONCLUSION}

1. Based on the multi-field coupling theory of porous media and the mechanism of migration of coal seam gas, the mathematical model of the coal bed methane extraction is established. The calculation of the coupled model is simplified by the analysis of permeability evolution mechanism.

2. On the basis of geological data of coal bed methane wells in Shanxi Jincheng coal mine, the numerical model of extracting methane for a single well is established, the gas extraction process is simulated, compared with the historical data, and the simulation results are analyzed.

3. According to the comparison, when considering deformation of coal rock, yield curve from simulation changing of permeability and the actual production data of the $\mathrm{CHC} 38$ well are in better agreement. In the early stages of production, the gas rate of the case considering deformation of coal rock is lower than the case without considering, but the stable production period is longer. It is recommended to consider the deformation of the coal rock in the production prediction of CBM for JINcheng coal mine.

\section{CONFLICT OF INTEREST}

The authors confirm that this article content has no conflict of interest.

\section{ACKNOWLEDGEMENTS}

This work was financially supported by the open foundation project from state key laboratory of oil and gas reservoir geology and exploitation of Southwest Petroleum University (Grant No.PLN1131). The open foundation project from State Key Laboratory for Geo Mechanics and Deep Underground Engineering in China University of Mining \& Technology (Grant No.SKLGDUEK1308) provided us parts of equipment.

The theory of this research is inspired from the project (No.2014_3310, 2014_3334) from Work Safety Supervision Bureau of China and Natural Science Foundation of China (Grant No. 51208443), it is an application of the results of these research above.

The key project (Grant No. 13ZA0189) from Education Department of Sichuan Province and the project (Grant No. 2014QHZ036) from sail plan of Southwest Petroleum University provided us with some experimental method for reference.

Part of fund of the research is obtained from the open fund project (Grant No.ESP1406) from Ecological Security and Protection Key Laboratory of Sichuan Province (Mianyang Normal University).

Some basic parameters of the coal rock were provided by the science and technology innovation seedling project(Grant No.2015126) from Sichuan Province.

We appreciated these projects providers, because they offer us the requirement of finishing the research work in this paper, at the same time, we must express our thankfulness and salute to the authors of these references below.

\section{REFERENCES}

[1] T. Shi, X.F. Li, B.X. Yu, X.Y. Du, Y.Z. Li, S.M. Wen, and D.L. Zhang, "Review on desorption-diffusion-flow model of coal-bed methane", Scientia Sinica Physica", Mechanica \& Astronomica, vol. 43, pp. 1548-1557, 2013.

[2] W.A. Xufeng, Z. Dongsheng, L. Guojun, R. Tingxiang, and Z. Wei, "Methane drainage and utilization technologies for high gassy and low permeability coal seams in tiefa mining", Electronic Journal of Geotechnical Engineering, vol. 19, pp. 101-115, 2014.

[3] F.B. Gorucu, "Matrix shrinkage and swelling effects on economics of enhanced coalbed methane production and $\mathrm{CO}_{2}$ Sequestration in Coal", SPE Reservoir Evaluation \& Engineering, vol. 10, no. 4, pp. 382-392, 2007. [http://dx.doi.org/10.2118/97963-PA]

[4] A. Zarar, and Y. Bettan, "Interpretation of multiple hydraulically fractured horizontal wells in closed systems", SPE International Improved Oil Recovery Conference in Asia Pacific, Kuala Lumpur, Malaysia, 2003, pp. 221-234

[5] G.U. Liwen, K.A. Li, and Z. Jiayong, "Study on gas Experiment seepage features of seam in Qianjiaying Mine", Science and Technology Coal, vol. 43, pp. 60-63, 2015.

[6] Z.H. Qianguil, F.A. Xiangyu, and C.H. Ping, "Experimental study on gas flow and mechanical behaviors of coalbed near borehole under constant flow and CBM pressures", Journal of China University of Petroleum, vol. 39, pp. 38-45, 2015.

[7] Xiangchen Li, Kang, Li Yili, and Defei Chen, "Effect of Drillin fluids on CBM desorption, diffusion and percolation.Case study of A No.9 Coal Seam of the Ningwu Basin", Natural Gas Industrial, vol. 1, pp. 86-91, 2014. 
[8] Y.I. Guangzhi, J.I. Changbao, and X.U. Jiang, "Experimental study of influences for water content in coalbed gas reservoirs on methane seepage", Chinese Journal of Rock Mechanics and Engineering, vol. 30, pp. 3401-3406, 2011.

[9] L.I. Bo, W.E. Jianping, and W.A. Kai, "Experimental study of nonlinear motion law for gas seepage in coal seams", Chinese Journal of Rock Mechanics and Engineering, vol. 33, pp. 3219-3224, 2014.

[10] Z.H. Zhigang, and C.H. Bo, "Nonlinear equations of gas seepage in coal considering adsorption effect", Chinese Journal of Rock Mechanics and Engineering, vol. 34, pp. 1006-1012, 2015.

[11] L.I. Bing, Y.U. Xinpeng, and S.U. Weijiz, "Seepage coupling model of in-seam gas extraction and its applications", Journal of China University of Mining \& Technology, vol. 43, pp. 208-213, 2014.

[12] S.O. Li, S.O. Chun-jie, and F.A. Cheng, "Numerical simulations of MINING coal seam floor fluid-solid coupling failure caused by nonuniform distributed water pressure", Journal of Dalian University, vol. 36, pp. 36-40, 2015.

[13] S.O. Hongqing, Z.H. Weiyao, and W.A. Yibing, "Analytical model of low-velocity non-darcy flow of coalbed methane and its analysis", Journal of China University of Mining \& Technology, vol. 42, pp. 93-99, 2013.

[14] L.I. Guo-qing, M.E. Zhao-ping, and W.A. Bao-yu, "Diffusion and seepage mechanisms of high rank coal-bed methane reservoir and its numerical simulation at early drainage rate", Journal of China Coal Society, vol. 39, pp. 1919-1926, 2014.

[15] Z.H. Yongli, Z.H. Lele, and M.A. Yulin, "Simulation for desorption and seepage rules of numerical coalbed mathane considering temperature conditions", Journal of Disaster Prevention and Mitigation Engineering, vol. 34, pp. 671-677, 2014.

[16] X.U. Jiang, Z.H. Tine, and L.I. Bohol, "Experimental research on seepage lagging effects of coalbed methane reservoir under condition of triaxial stress", Chinese Journal of Rock Mechanics and Engineering, vol. 31, pp. 1854-1861, 2012.

[17] J.I. Nannan, J. Longzhe, and C. Shaojie, "Study on seepage law for the front of gas displacement by coal seam water injection", Safety in Coal Mines, vol. 46, pp. 16-19, 2015.

[18] Y.A. Duoxi, and L.U. Haifeng, "Seepage field-strain field coupling analysis for rock masses of coal seam floor during mining above a confined aquifer", Chinese Journal of Rock Mechanics and Engineering, vol. 31, pp. 2736-2742, 2012.

[19] F. Gu, and J. Chalaturnyk, "Analysis of coalbed methane production by reservoir and geomechanical coupling simulation", Journal of Canadian Petroleum Technology, vol. 44, pp. 1-10, 2005.

[20] L.D. Connell, and C. Detournay, "Coupled flow and geomechanical processes during enhanced coal seam methane recovery through $\mathrm{CO}_{2}$ sequestration", International Journal of Coal Geology, vol. 77, pp. 222-233, 2009. [http://dx.doi.org/10.1016/j.coal.2008.09.013]

C Likai et al.; Licensee Bentham Open

This is an open access article licensed under the terms of the Creative Commons Attribution-Non-Commercial 4.0 International Public License (CC BY-NC 4.0) (https://creativecommons.org/licenses/by-nc/4.0/legalcode), which permits unrestricted, non-commercial use, distribution and reproduction in any medium, provided the work is properly cited. 